\title{
Characterization of a cryptic plasmid isolated from Lactobacillus casei CP002616 and construction of shuttle vectors based on its replicon
}

\author{
Xin Song, ${ }^{*}$ He Huang, $†$ Zhiqiang Xiong, ${ }^{*}$ Yongjun Xia, ${ }^{*}$ Guangqiang Wang, ${ }^{*}$ Boxing Yin,‡ and Lianzhong $\mathrm{Ai}^{* 1}$ \\ *Shanghai Engineering Research Center of Food Microbiology, School of Medical Instrument and Food Engineering, \\ University of Shanghai for Science and Technology, Shanghai 200093, China \\ tKey Lab of Synthetic Biology, Institute of Plant Physiology and Ecology, Shanghai Institutes for Biological Sciences, \\ Chinese Academy of Sciences, Shanghai 200032, China \\ $\ddagger$ Kangyuan Dairy Co. Ltd., Yangzhou University, Yangzhou 225004, China
}

\section{ABSTRACT}

The cryptic plasmid pLC2W was isolated from Lactobacillus casei CP002616. Nucleotide sequence analysis revealed that 4 putative open reading frames (ORF) were responsible for DNA replication. Four Escherichia coli-Lactobacillus shuttle vectors were constructed using different lengths of the pLC2W replicon to identify the shortest functional replicon. The length of the pLC2W replicon did not affect the stability of the plasmids. Green fluorescent protein (GFP) as a reporter was expressed successfully in several lactobacilli using our constructed vectors. The results suggested that the expression vectors pUE-F0GFP and pUE-F1GFP are potential molecular tools for heterologous gene cloning and expression in lactobacilli. Moreover, 2 plasmidcuring methods were used to eliminate $\mathrm{pLC} 2 \mathrm{~W}$ from $L$. casei. We detected no difference between $L$. casei CP002616 and L. casei CP002616 pLC2W $\Delta-\mathrm{IC}$ (mutant strain cured by plasmid incompatibility method) in production of exopolysaccharide (EPS) or acid. However, EPS and acid production were both reduced in L. casei CP002616 pLC2W $\Delta-\mathrm{HT}$ (mutant strain cured by high-temperature heat treatment method), demonstrating a difference between these 2 curing methods. Sequence analysis of $\mathrm{pLC} 2 \mathrm{~W}$ and plasmid curing data suggest that plasmid pLC2W is not involved in EPS synthesis.

Key words: cryptic plasmid pLC2W, shuttle vector, Lactobacillus casei, expression vector, cure plasmid

\section{INTRODUCTION}

Lactic acid bacteria (LAB) are widespread in natural environments. They play important roles in human

Received August 30, 2017.

Accepted October 19, 2017.

${ }^{1}$ Corresponding author: ailianzhong@hotmail.com health and the human gastrointestinal tract with a long history (de Vos, 2011; Bourdichon et al., 2012; Gaspar et al., 2013). Lactic acid bacteria can improve lactose digestion, enhance cellular immunity, help to cure disease in humans, and protect against colon cancer (Wen et al., 2012; Chen et al., 2014; Aktas et al., 2016; Gleeson et al., 2016; Kato-Kataoka et al., 2016). Although $\mathrm{LAB}$ are useful in many applications, the mechanism by which lactobacilli contribute to other bacteria and hosts remains obscure (Vaughan et al., 2000). Many researchers have focused on the genetic mechanisms in $\mathrm{LAB}$, and a wide range of genetic tools have been developed in LAB and successfully applied in several LAB (Mathiesen et al., 2004).

Because genetic elements in LAB are related to plasmids, shuttle plasmids have been constructed and applied to express important genes. Plasmids isolated from LAB are the best choice as the backbone of shuttle vectors. Recently, many cryptic plasmids have been isolated from LAB, including pCD01 and pCD02 from Lactobacillus paracasei (Desmond et al., 2005), pLC494 from Lactobacillus casei (An and Miyamoto, 2006), pRV500 from Lactobacillus sakei (Crutz-Le Coq and Zagorec, 2008), pDOJ1 from Lactobacillus delbrueckii (Lee et al., 2007), pM4 from Lactobacillus plantarum (Yin et al., 2008), and pBC1 from Bifidobacterium catenulatum (Alvarez-Martín et al., 2007). Many shuttle vectors have been constructed based on these cryptic plasmids. Most Lactobacillus plasmids duplicate via a theta or rolling circle (RC) mechanism, including the plasmids mentioned above. Theta-type plasmids can accommodate insertions of larger DNA fragments than RC-type plasmids.

Some reports have noted that plasmids in lactobacilli are involved in production of exopolysaccharides (EPS; Vedamuthu and Neville, 1986). To study the relationship between pLC2W and EPS production, we used 2 plasmid-curing methods for pLC2W. The current common approach for curing plasmid is a high- 
temperature method, which is cumbersome and time consuming (Yin et al., 2008; Sun et al., 2010; Chen et al., 2014). Mutations may occur during the harsh physical curing process. For these reasons, we also used a new rapid and high-efficiency curing method based on plasmid incompatibility - the inability of 2 plasmids with the same replicon to coexist stably in the same host (Liu et al., 2012). Introducing a smaller plasmid with the same replicon will cure the original plasmid, especially if antibiotics are also present. This method has been successfully used in many strains to generate plasmid-free mutants (Uraji et al., 2002; Ni et al., 2008; Liu et al., 2012) and is a powerful and robust method of plasmid curing.

We recently isolated a new $L$. casei strain from traditional dairy products in Inner Mongolia designated L. casei CP002616. The aims of the current study were (1) to predict the replication mechanism of pLC2W (a cryptic plasmid isolated from $L$. casei CP002616) using phylogenetic analysis of the replication protein; and (2) to confirm the shortest functional replicon by constructing a series of plasmids based on different lengths of the $\mathrm{pLC} 2 \mathrm{~W}$ putative replicon. We determined the host range of the new shuttle vector and constructed a new expression vector based on it. We also used 2 methods to cure plasmid of L. casei CP002616 and compared the production of EPS and acid in L. casei CP002616 and mutants.

\section{MATERIALS AND METHODS}

\section{Bacterial Strains, Enzymes, and Kits}

All plasmids were introduced into competent Escherichia coli cells (E. coli Top10, Takara, Tokyo, Japan) grown in Luria-Bertani broth $(\mathbf{L B})$ medium at $37^{\circ} \mathrm{C}$. The strains and plasmids used in this study are shown in Table 1. Lactobacillus strains were grown in de Man, Rogosa, and Sharpe (MRS) medium (1 L of the medium contained $10.0 \mathrm{~g}$ of peptone, $10.0 \mathrm{~g}$ of beef extract, $4.0 \mathrm{~g}$ of yeast extract, $20.0 \mathrm{~g}$ of glucose, $1 \mathrm{~mL}$ of Tween-80, $2.0 \mathrm{~g}$ of dipotassium hydrogen phosphate, $5.0 \mathrm{~g}$ of sodium acetate, $2.0 \mathrm{~g}$ of triammonium citrate, $0.2 \mathrm{~g}$ of magnesium sulfate, and $0.05 \mathrm{~g}$ of manganese sulfate) at $37^{\circ} \mathrm{C}$ (Lactococcus lactis was grown at $30^{\circ} \mathrm{C}$ ) and $\mathrm{pH} 6.2$ without shaking. Antibiotics were used, when necessary, as follows: ampicillin (Amp; Sangon Biotech, Shanghai, China) at $100 \mu \mathrm{g} / \mathrm{mL}$ for E. coli; erythromycin (Em; Sangon Biotech) at $200 \mu \mathrm{g} / \mathrm{mL}$ for E. coli and $10 \mu \mathrm{g} / \mathrm{mL}$ for Lactobacillus.

The PCR used KOD-plus-neo DNA polymerase (Toyobo, Osaka, Japan) or KOD FX polymerase (Toyobo). A ClonExpress MultiS One Step Cloning Kit (Vazyme Biotech Co. Ltd., Nanjing, China) and DNA restriction enzymes (Thermo Fisher Scientific, Waltham, MA) were used to prepare clones. Plasmids and chromosomal DNA of E. coli were extracted using

Table 1. Bacterial strains and plasmids

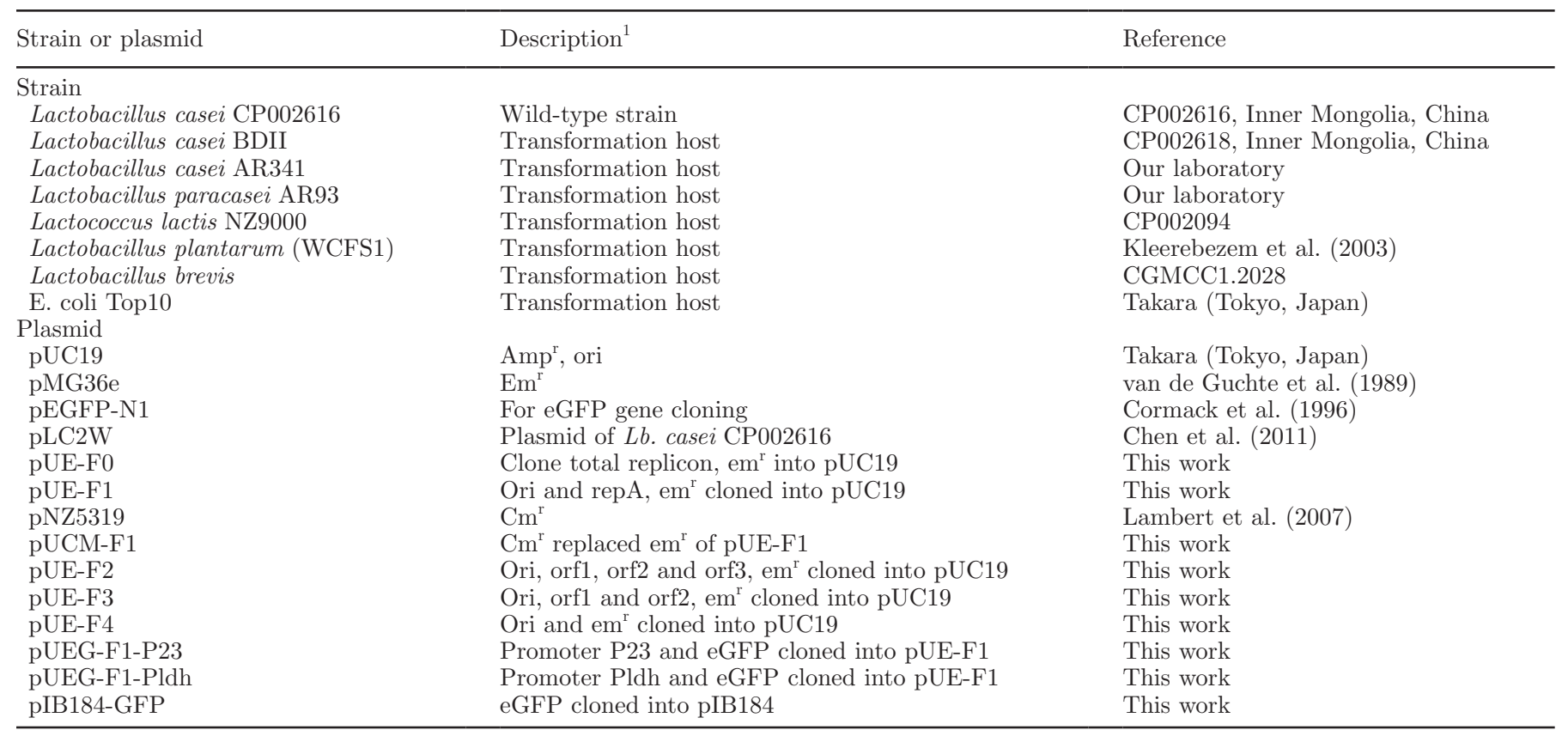

${ }^{1} \mathrm{Amp}^{\mathrm{r}}=$ ampicillin resistance; ori $=$ origin $; \mathrm{Em}^{\mathrm{r}}=$ erythromycin resistance; eGFP $=$ enhanced green fluorescent protein; rep $=$ replicon; $\mathrm{Cm}^{\mathrm{r}}=$ chloramphenicol resistance; orf = open reading frame. 
kits (Axygen Biotechnology Co. Ltd., Hangzhou, China). Plasmids of Lactobacillus were extracted according to the method described by O'Sullivan and Klaenhammer (1993), and genomic DNA of Lactobacillus was extracted by a method described previously (Chen et al., 2014). All enzymes were used following the instructions of the manufacturers.

\section{Sequence Analysis of Replication Initiation Protein}

To assess the replication mechanism of $\mathrm{pLC} 2 \mathrm{~W}$, we compared the AA sequence of the replication initiation (Rep) protein of pLC2W with those of Rep proteins in the theta-type plasmids and RC plasmids in Lactobacillus. The Rep sequences were first aligned using Clustal $\mathrm{X}$ software (version 2.0, Conway Institute University College Dublin, Ireland; Larkin et al., 2007), and a phylogenetic tree was constructed by the neighbor-joining method using MEGA software (version 6.0, Biodesign Institute, Arizona State University, Tempe, AZ). The bootstrap consisted of 1,000 replications to assess the reliability level of the nodes of the tree (Tamura et al., 2007).

\section{Electroporation Transformation}

Competent cells of $L$. casei and L. paracasei were prepared as follows: $2.5 \mathrm{~mL}$ of overnight culture was inoculated in $50 \mathrm{~mL}$ of MRS with $1 \%$ glycine (MRSG) and incubated at $37^{\circ} \mathrm{C}$ without shaking until the optical density at $600 \mathrm{~nm}\left(\mathrm{OD}_{600}\right)$ reached 0.6 to 0.8 . Cells were harvested by centrifugation at $5,000 \times g$ for $10 \mathrm{~min}$. Cells were washed twice in an ice-cold washing solution containing $10 \%$ glycerol, with centrifugation at 5,500 $\times g$ for $10 \mathrm{~min}$. The cells were then resuspended in 0.5 $\mathrm{mL}$ of the same solution for electroporation. For each transformation, $50 \mu \mathrm{L}$ of cell suspension was mixed with $\sim 100 \mathrm{ng}$ of plasmid DNA and incubated on ice for $10 \mathrm{~min}$. The mixture was then transferred to a $2-\mathrm{mm}$ cuvette (Bio-Rad Laboratories, Hercules, CA), and electroporation was performed at $2 \mathrm{kV}, 200 \mathrm{k} \Omega$, and $25 \mu \mathrm{F}$, using an Eppendorf Multiporator (Eppendorf, Hamburg, Germany). Then, $950 \mu \mathrm{L}$ of warmed MMRS broth (MRS $+500 \mathrm{mmol} / \mathrm{L}$ saccharose $+20 \mathrm{mmol} / \mathrm{L}$ $\mathrm{MgCl}_{2}+2 \mathrm{mmol} / \mathrm{L} \mathrm{CaCl}_{2}$ ) was added to the cuvette, and the transformed cells were allowed to recover by incubation at $37^{\circ} \mathrm{C}$ for 2 to $3 \mathrm{~h}$. The cells were then plated on MRS agar plates with erythromycin to recover transformants. Transformation rates were expressed as the number of transformants per microgram of plasmid DNA. Competent cells of $L$. plantarum WCFS1 and $L$. lactis NZ9000 were prepared as the method described previously (Serror et al., 2002; Papagianni et al., 2007; Luxananil et al., 2009; Yin et al., 2009).

\section{Determination of Plasmid Copy Number}

Relative copy numbers of pLC2W and its derived plasmids in L. casei CP002616 and other L. casei strains were estimated using real-time quantitative PCR (qPCR) using SYBR Green (Bio-Rad Laboratories) and MyIQ2 (Bio-Rad). The elongation factor gene $D n a A$ was used as a chromosomal reference, and repA of pLC2W was used as the target gene. Primers for qPCR were designed using Primer Premier 5.0 software (Premier Biosoft, Palo Alto, CA) to give PCR products of similar sizes. A 126-bp product was designed for repA and an 84-bp product was designed for DnaA, with the primers listed in Table 2. The copy number of pLC2W was calculated using the formula: plasmid copy number $(\mathrm{PCN})=\mathrm{Ep}^{\text {(Ctc - Ctp) }}$ (Skulj et al., 2008), where $\mathrm{E}$ represents the PCR amplification efficiency of the target, $\mathrm{p}$ and $\mathrm{c}$ indicate plasmid and chromosome respectively, and $\mathrm{Ct}$ indicates = cycle threshold value; E could be calculated using the slope of the standard curve and the equation $\mathrm{E}=10^{-1 / \text { slope }}(\mathrm{E}$ was 2 when the product amplified at 100\% efficiency; Pfaffl, 2001).

\section{Construction of E. coli-Lactobacillus Shuttle Vectors}

The oligonucleotide primers used for the construction of the cloning vector are listed in Table 2. Plasmid pUC19 was double-digested with $S a c$ I and BamHI. The Em resistance gene was amplified by PCR using the primers EmF and EmR, and pMG36e as the template. Then, DNA fragments of different lengths were produced by PCR amplification using pLC2W DNA as the template. All DNA fragments were ligated by T4 Ligase (Sangon Biotech). Plasmids were constructed using different lengths of the pLC2W replicon.

The Em resistance gene of pUE-F1 was replaced in a 2-step process by a chloramphenicol $(\mathbf{C m})$ resistance gene from pNZ5319, giving rise to pUCM-F1. The availability of constructs with different antibiotic selections allowed the consecutive transformation of pUE-F1 and pUCM-F1 into LAB.

\section{Host Range and Segregation Stability}

The concentrations of plasmid DNA used for transformation were quantified using a spectrophotometer (NanoDrop 2000, Thermo Fisher Scientific). One hundred nanograms of plasmid was used to transform into L. casei CP002616, L. casei AR341, L. casei BD II, L. paracasei AR93, L. plantarum WCFS1, L. brevis CGMCC1.2028, and Lc. lactis NZ9000 by electroporation. The transformation efficiency was measured by calculating the transformants per microgram of DNA (Sun et al., 2010). 
To determine the segregation stability of the vectors, plasmid-bearing stains were grown overnight in MRS with Em, and $1 \%$ of the overnight culture was inoculated into MRS without antibiotic. After incubation for about 20, 40, 60 or 80 generations, counts (cfu) were determined by using nonselective and selective MRS agar plates. Ratios of counts on the selective to nonselective plates were used to estimate the stability of different plasmids as described previously (AlvarezMartín et al., 2007; Sun et al., 2010; Chen et al., 2014).

\section{Construction of Expression Vector}

To construct a new expression vector with pUE-F1, 3 additional DNA elements were required; namely, a promoter element and 2 multiple cloning sites. The $\mathrm{P}_{23}$ promoter was amplified by using primers $\mathrm{P} 23$-up and P23-down, and plasmid pIB184 was used as the template. To verify that the vector was an effective reporter system in $L$. casei, the lactic dehydrogenase $(l d h)$ promoter was amplified with primers pldh-up and pldh-down, and L. casei CP002616 genomic DNA was used as a template. An enhanced green fluorescent protein (eGFP) gene was amplified from plasmid pEGFPN1 (Cormack et al., 1996) with primers GFP-up and GFP-down. All primer pairs are listed in Table 2. The 4 amplicons were then cloned into pUE-F1 with double digests at SpeI and BamHI to obtain 2 new plasmids: pUEG-F1-P 23 and pUEG-F1-P ${ }_{\text {ldh }}$.
The efficiencies of the different promoters in $L$. casei CP002616 were estimated using qPCR. The elongation factor gene DnaA (GenBank accession no. 501467306) was used as a chromosomal reference, and GFP was used as the target gene.

\section{Plasmid Curing from L. casei CP002616}

Two different methods of plasmid curing were used to eliminate pLC2W. For the HT method, L. casei CP002616 was propagated in MRS at $42^{\circ} \mathrm{C}$ for about 200 generations. Then, the culture was diluted and plated on MRS plates. To identify plasmid-free clones, colony PCR was conducted using primers (repA-up/ down) that can amplify the fragment only present in the plasmid. For the IC method, the incompatible plasmid pUE-F1 was transferred into competent cells of $L$. casei CP002616 by electroporation. Cells were grown on MRS plates with Em for $48 \mathrm{~h}$. One positive transformant along with pUE-F1 grew in MRS with Em for at least 5 culture passages. Antibiotic concentration increased 1.5 times when cells were transferred each time. The culture was diluted and plated on MRS-Em plates, and positive transformants were selected using primers (rmp-up/down) that can amplify the pLC2W specific fragment.

To obtain a plasmid-cured strain without exogenous DNA, we needed to cure pUE-F1 from pLC2W-cured L. casei CP002616. The host was propagated twice in 4

Table 2. Oligonucleotides and primers ${ }^{1}$

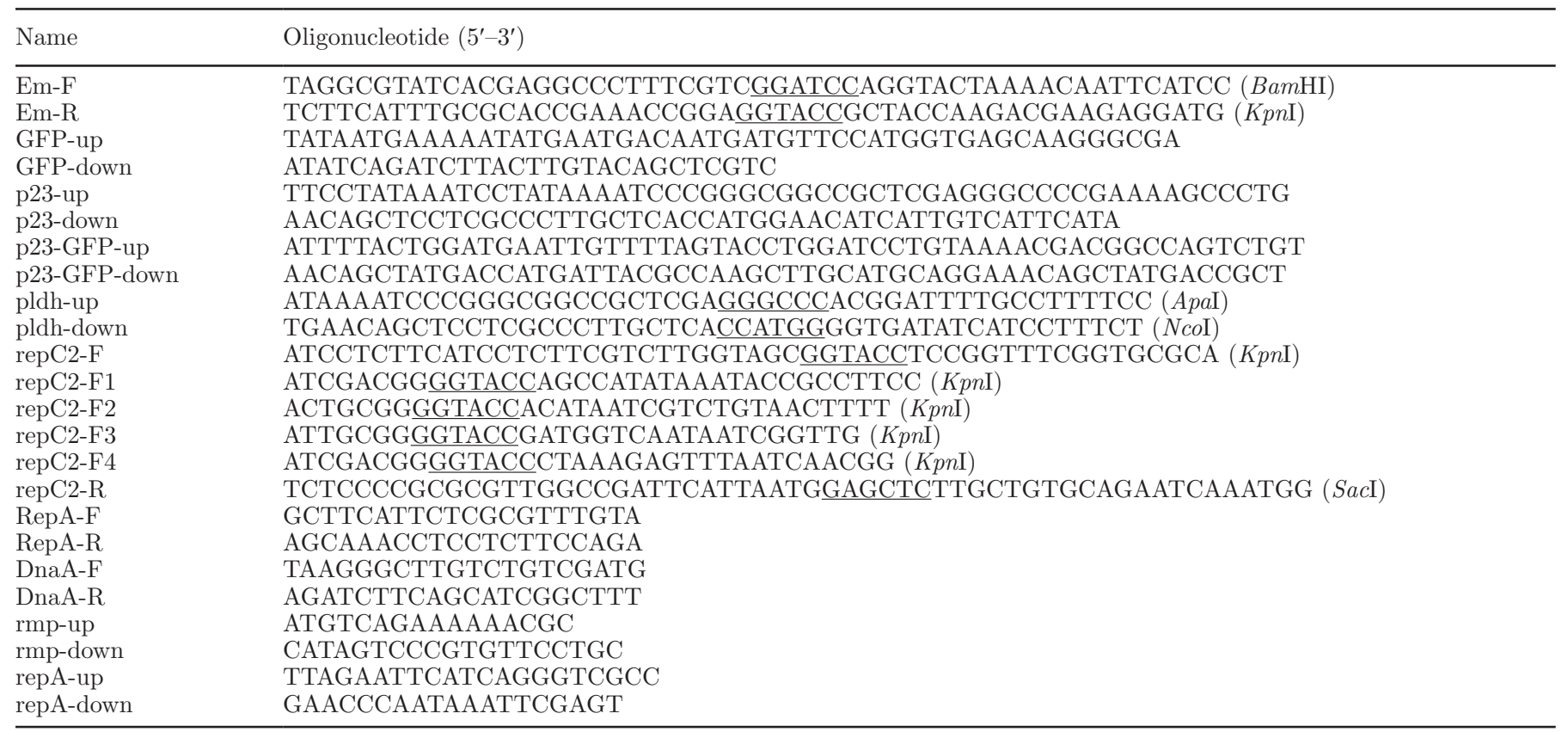

\footnotetext{
${ }^{1}$ Underlining indicates digestion sites.
} 
$\mathrm{mL}$ of MRS without antibiotics. Cultures were diluted and spread on MRS plates without antibiotics for $48 \mathrm{~h}$. Clones were streaked onto MRS plates with or without erythromycin and incubated at $37^{\circ} \mathrm{C}$ for $36 \mathrm{~h}$.

\section{EPS and Acid Production}

To analyze the EPS production of the mutant strains, fermentation was carried out with $L$. casei CP002616 pLC2W $\Delta$-HT, L. casei CP002616 pLC2W $\Delta$-IC, and $L$. casei CP002616 strains in $30 \mathrm{~mL}$ of liquid MRS medium for $24 \mathrm{~h}$. The cells were removed by centrifugation at $10,000 \times g$ for $20 \min \left(4^{\circ} \mathrm{C}\right)$, and EPS was precipitated from the supernatant with cold $95 \%$ ethanol for $24 \mathrm{~h}$ at $4^{\circ} \mathrm{C}$. The EPS fraction was resuspended in ultrapure water $(10 \%$, wt $/$ wt) after centrifugation $(10,000 \times g, 20$ min, $4^{\circ} \mathrm{C}$ ), and EPS was dialyzed against water for 72 $\mathrm{h}$ using a membrane with molecular weight cut-off of 12,000 to $14,000 \mathrm{Da}$. The production of EPS was evaluated as previously described (Lokman et al., 1997). The different types of EPS from L. casei CP002616 pLC2W $\Delta$-HT, L. casei CP002616 pLC2W $\Delta$-IC, and L. casei CP002616 were named EPS-HT, EPS-IC, and EPS-WT, respectively.

High-performance anion exchange chromatography coupled with pulsed amperometric detection (HPAECPAD; Dionex ICS-5000 System, Dionex Corporation, Sunnyvale, CA) was used to identify and quantify monosaccharides of EPS-HT, EPS-IC, and EPS-WT. The EPS were dissolved in $0.5 \mathrm{~mL}$ of $12 \mathrm{M} \mathrm{H}_{2} \mathrm{SO}_{4}$ at an ice bath for $30 \mathrm{~min}$, and then diluted to $3 \mathrm{~mL}(2 \mathrm{M}$ $\mathrm{H}_{2} \mathrm{SO}_{4}$ ) to further hydrolyze for $2 \mathrm{~h}$ at $100^{\circ} \mathrm{C}$. Separation was performed on a CarboPac PA20 column (3 $\mathrm{mm} \times$ $150 \mathrm{~mm}$, Dionex Corp.) and a CarboPac PA20 Guard (3 mm $30 \mathrm{~mm}$, Dionex Corp.) with a gradient elution procedure at a flow rate of $0.5 \mathrm{~mL} / \mathrm{min}$ at $30^{\circ} \mathrm{C}$. The eluents consisted of $250 \mathrm{mM} \mathrm{NaOH}$ solution (A), distilled water (B), and $1 M$ sodium acetate (C). Initially, $0.8 \%$ A was eluted for $20 \mathrm{~min}$, followed by a gradient increase from $5 \% \mathrm{C}$ to $20 \% \mathrm{C}$ while maintaining $0.8 \%$ A. Finally, $80 \%$ A was eluted to regenerate the column for 20 min (Yuan et al., 2015). Chromeleon software (Dionex Corp.) was used to process the data.

The molecular weight distributions of EPS-HT, EPS-IC, and EPS-WT were determined by high-performance gel-permeation chromatography using a Waters instrument (Waters Corp., Milford, MA) equipped with a refractive index detector (Waters 2414), a variable wavelength detector (Waters 2489), and an Ultrahydrogel Linear column $(7.8 \times 300 \mathrm{~mm}$; Waters Corp.). The polysaccharides were eluted with $0.1 \mathrm{M}$ sodium nitrate at a flow rate of $0.6 \mathrm{~mL} / \mathrm{min}$. The column temperature was maintained at $35.0 \pm 0.5^{\circ} \mathrm{C}$. The polysaccharides were filtered through a $0.45-\mu \mathrm{m}$ membrane before injection. The molecular weight of the samples was calculated according to the calibration curve established using dextran standards $\left(2 \times 10^{6}, 300,600,135,350,64,650\right.$, $36,800,13,050$, and 9,750$)$.

To determine the acid production of the mutants, freshly grown overnight cultures of L. casei CP002616 pLC2W $\Delta$-HT, L. casei CP002616 pLC2W $\Delta$-IC, and $L$. casei CP002616 were inoculated into MRS at $2 \%$ and incubated at $37^{\circ} \mathrm{C}$. The change in $\mathrm{pH}$ was monitored using a $\mathrm{pH}$ meter every $2 \mathrm{~h}$.

\section{RESULTS}

\section{Molecular Characterization of pLC2W}

Plasmid pLC2W is a native plasmid of $L$. casei CP002616 isolated from traditional dairy products in Inner Mongolia. The plasmid was $38,392 \mathrm{bp}$ with a GC content of $42.64 \%$ (Chen et al., 2011); it was predicted to have 4 putative open reading frames (ORF). Analysis of the AA sequences of these ORF showed that they shared $100 \%$ identity with the replication proteins on pBD II and pW56 (Ai et al., 2011; Hochwind et al., 2012): ORF1 (351 AA) was identified as a replication protein (RepA), ORF2 (278 AA) was identified as a replication-associated protein (RepB), and ORF3 (129 AA) and ORF4 (113 AA) were identified as hypothetical proteins with unknown functions.

Strikingly, RepA and RepB had very low sequence similarity to each other, exhibiting $44 \%$ identity and 10\% coverage using National Center for Biotechnology Information blastp (Protein BLAST; https://blast.ncbi .nlm.nih.gov/Blast.cgi). A phylogenetic tree was constructed using the AA sequences of RepA and the other 11 Rep proteins from the Lactobacillus plasmids that replicate via theta or $\mathrm{RC}$ replication (Figure 1). Based on phylogenetic analysis, RepA of pLC2W was from the $\mathrm{RC}$ replication group; therefore, we reasoned that the replicon of $\mathrm{pLC} 2 \mathrm{~W}$ could replicate via $\mathrm{RC}$ replication.

\section{Shortest Functional Replicon and Copy Number of $p L C 2 W$ and Derivatives}

To investigate the shortest functional replicon of pLC2W, we constructed a series of shuttle plasmids (pUE-F0, pUE-F1, pUE-F2, pUE-F3, and pUE-F4) with different sizes of pLC2W replicon (Figure 2a). These plasmids were checked on LB plates containing Amp. Subsequently, the recombined plasmids were transformed into L. casei CP002616 to study the origin activity of the different fragments. The stability of these shuttle plasmids was then estimated by scoring 
for plasmid-free colonies after continuous incubation in MRS for several generations under nonselective conditions. The results are summarized in Table 3.

Four shuttle plasmids (all except pUE-F4) with different lengths of replicon in $L$. casei CP002616 formed Em-resistant colonies. The transformation efficiency of these plasmids was about $10^{5} \mathrm{cfu} / \mu \mathrm{g}$ of DNA, and we detected no significant difference in stability between the shuttle plasmids. In summary, the minimal replicon comprised the origin (Ori) and RepA, and replication activity required both elements. Plasmid pUCM-F1 was obtained for the consecutive transformation of pUE-F1 and pUCM-F1 into LAB (Figure 2b).

The qPCR was used to determine the relative copy numbers of $\mathrm{pLC} 2 \mathrm{~W}$ and its derived shuttle plasmids in Lactobacillus cells. Two sets of primers were designed to generate PCR products for the repA and DnaA genes, which were used to quantify plasmids and chromosomes in the samples, respectively. Analysis of the results revealed that the copy number of $\mathrm{pLC} 2 \mathrm{~W}$ was 4.82 copies per cell. The estimated copy number of the derived plasmid pUE-F1 in L. casei CP002616 was 33.9 copies per cell.

\section{Host Range and Segregation Stability}

Because we detected no significant difference between the constructed plasmids, we selected pUE-F1 for transforming into different Lactobacillus strains to study the host range. The tested strains included L. casei CP002616, L. plantarum WCFS1, L. brevis (CGMCC 1.2028), L. casei BDII, L. casei AR341, L. paracasei AR93 and Lactococcus lactis NZ9000. Plasmid pUE-F1 survived in L. casei CP002616, L. casei BDII, L. casei AR341, Lc. lactis NZ9000, and L. paracasei AR93, but did not survive in L. plantarum WCFS1 or L. brevis (CGMCC 1.2028). The efficiencies ranged between $10^{2}$ and $2.2 \times 10^{5} \mathrm{cfu} / \mu \mathrm{g}$ DNA (Table 4). We then assessed stability of the pLC2W-derived shuttle plasmids in different hosts; pUE-F1 was unstable in $L$. casei CP002616, L. casei BDII, and L. casei AR341 but stable in L. paracasei AR93. The stability of pUE-F1 in Lc. lactis NZ9000 was not estimated in this work.

\section{Expression of the GFP Gene in a Lactobacillus Host}

Two strong promoters $\left(\mathrm{P}_{23}\right.$ and $\left.\mathrm{P}_{\text {ldh }}\right)$ were used to construct new expression vectors, named pUEG-F1-P 23 and pUEG-F1- $\mathrm{P}_{\text {ldh }}$ (Figure 2c). These plasmids were transformed into competent cells of L. casei CP002616 and Lc. lactis NZ9000 (Figure 3a and b). Green fluorescence was observed in several recombinant cells. To further determine GFP expression of different promoters, we used qPCR for quantitative analysis. Expression of GFP in pUEG-F1- $\mathrm{P}_{\text {ldh }}$ was defined as 1 , and the expression of pIB184-GFP and pUEG-F1- ${ }_{23}$ was 1.804 and 1.027, respectively (Figure 3c). We detected no significant difference in GFP expression between promoters $\mathrm{P}_{23}$ and $\mathrm{P}_{\text {ldh }}$.

\section{Plasmid Curing from L. casei CP002616}

To study the relationship between plasmid and EPS production in L. casei CP002616, we cured pLC2W using 2 different methods and compared them. For the HT method, colonies were confirmed by colony PCR with primers (repA-up/down) after propagation for 100 generations at $42^{\circ} \mathrm{C}$. Result showed that with primers (repA-up/down), some colonies amplified lowproduction DNA fragments but most of them amplified normal production. Colonies with low production were propagated further at $42^{\circ} \mathrm{C}$ and confirmed by colony

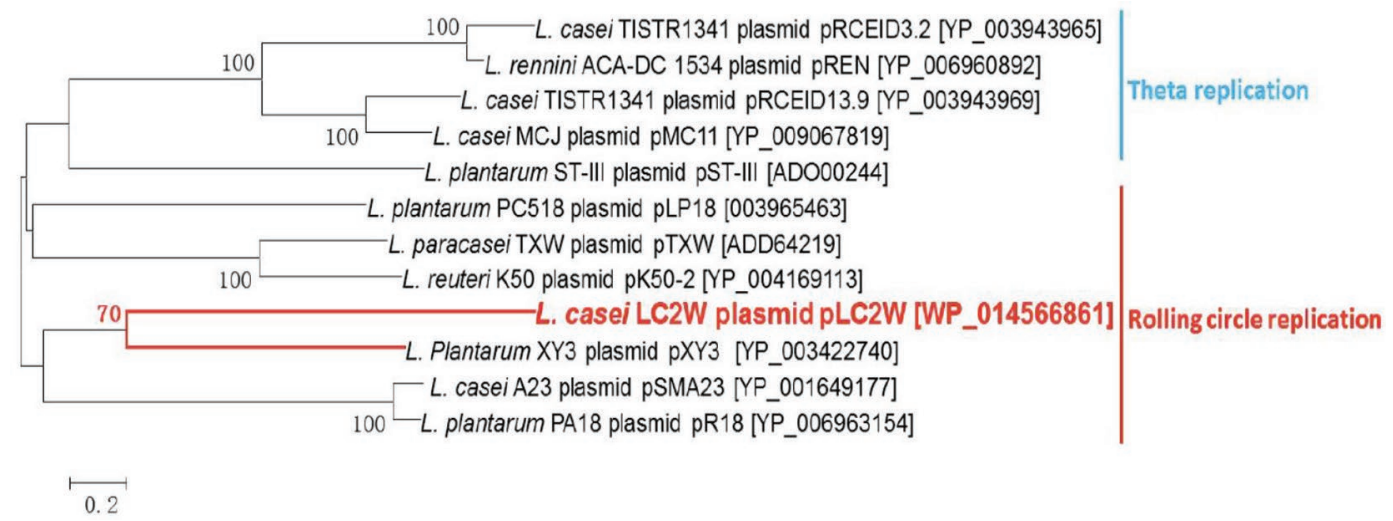

Figure 1. Phylogenetic tree for the replication initiation (Rep) proteins from different plasmids constructed using MEGA 6.0 (Biodesign Institute, Arizona State University, Tempe, AZ). The phylogenetic tree, made using MEGA 6.0, classified the Rep proteins from different plasmids. Color version available online. 
(a)
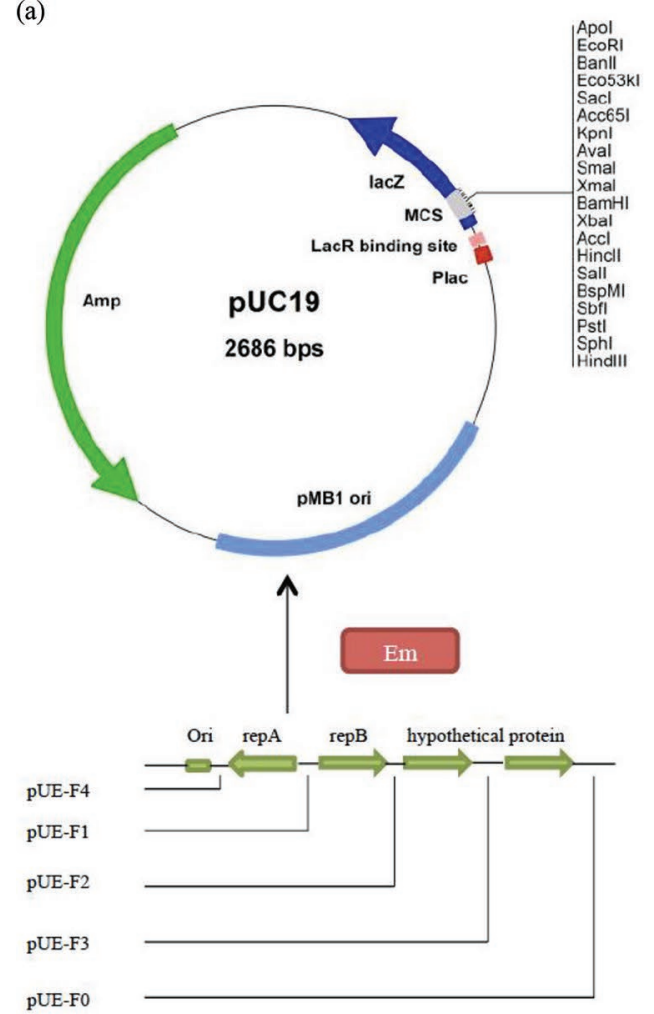

(b)

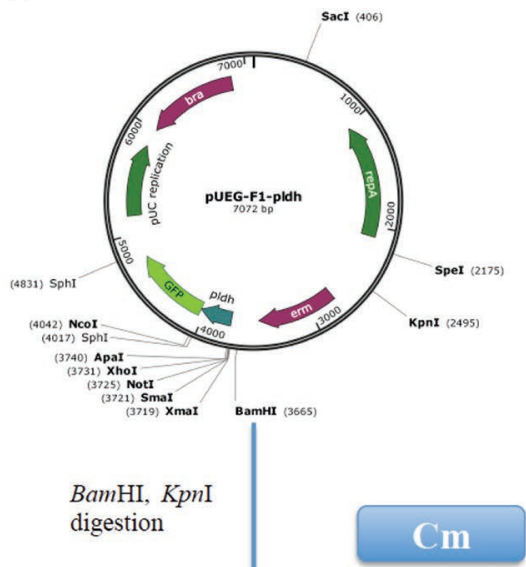

Cm from pNZ5319 (digested

by BamHI, KpnI

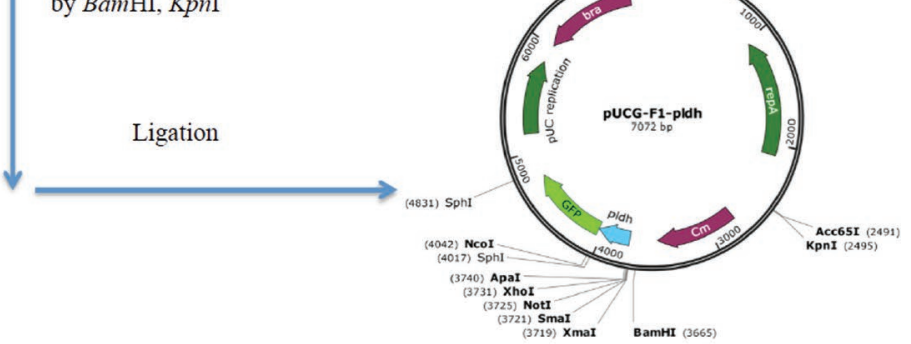

(c)

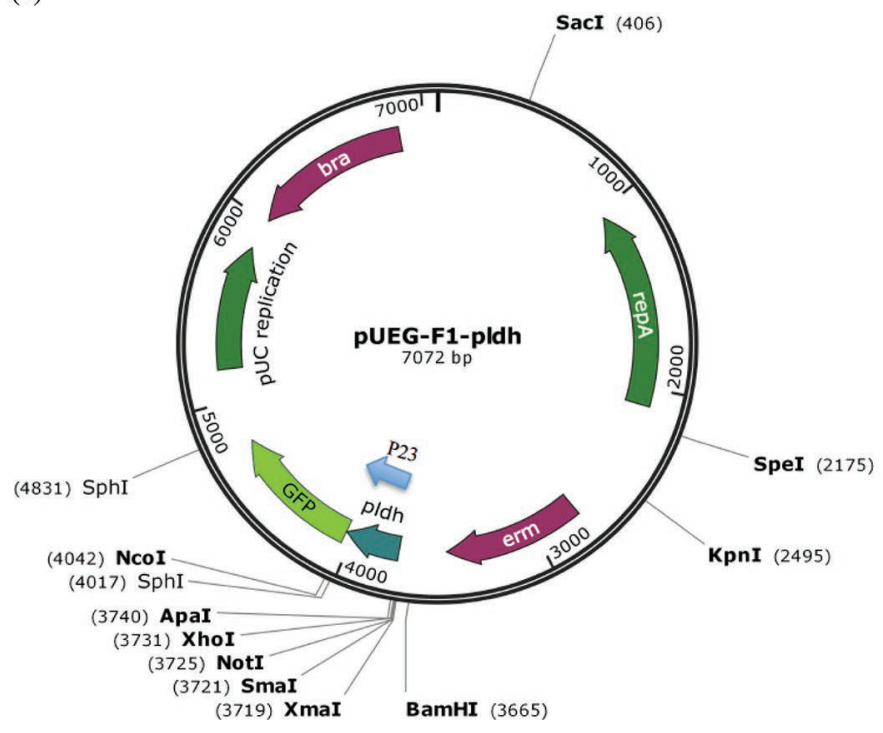

Figure 2. (a) Construction of the shuttle vectors pUE-F0, pUE-F1, pUE-F2, pUE-F3, pUE-F4; (b) construction of pUCG-F1-P ldh $_{\text {; }}$ (c) pUEG-F1-P $\mathrm{P}_{\mathrm{ldh}}$ and pUEG-F1-P ${ }_{23}$. Amp = ampicillin; Ori = origin; Em = erythromycin; GFP = green fluorescent protein; Cm = chloramphenicol; orf $=$ open reading frame; pldh and $\mathrm{P} 23=$ promoters; LacZ $=\beta$-galactosidase; $\mathrm{MCS}=$ multiple cloning site; LacR $=$ lac repressor binding site; Plac $=$ promoter of LacZ; and bra $=$ ampicillin. Color version available online.

PCR. When primers (repA-up/down) could not amplify DNA from L. casei CP002616 colonies, we obtained positive mutants and named them L. casei CP002616 pLC2W $\Delta$-HT (Figure 4a).
For the IC method, the recombinant plasmid pUEF1 was introduced into L. casei CP002616 and positive transformants were confirmed by colony PCR with primers (rmp-up/down). The positive colonies con- 
Table 3. Transformation efficiency (cfu/ $\mu \mathrm{g}$ of DNA) and stability (as plasmid loss rate) of the shuttle vectors in Lactobacillus casei CP002616

\begin{tabular}{|c|c|c|c|c|c|}
\hline Item & \multicolumn{5}{|c|}{ Plasmid } \\
\hline $\begin{array}{l}\text { Efficiency }(\mathrm{cfu} / \mu \mathrm{g} \text { of DNA) } \\
\text { Plasmid loss rate }(\%)\end{array}$ & $1.8 \times 10^{5}$ & $2 \times 10^{5}$ & $1.3 \times 10^{5}$ & $8.6 \times 10^{5}$ & - \\
\hline After 20 generations & 1.96 & 2.24 & 2.2 & 1.98 & - \\
\hline After 40 generations & 10.23 & 9.67 & 9.5 & 10.18 & - \\
\hline After 60 generations & 35.12 & 33.87 & 35.43 & 35.63 & - \\
\hline
\end{tabular}

tained 2 plasmids, the cryptic plasmid $\mathrm{pLC} 2 \mathrm{~W}$ and the (introduced) competitor plasmid pUE-F1. Because of plasmid incompatibility, pUE-F1 substitution and pLC2W elimination could occur in the host cell after several generations under antibiotic pressure. Transformants grew in liquid MRS supplemented with Em for 5 culture passages at least. Transformants were confirmed by colony PCR using rmp-up/down as primers that amplified the special DNA fragment of $\mathrm{pLC} 2 \mathrm{~W}$ (Figure 4b). Positive colonies were designated L. casei CP002616 pUE-F1. Exogenous pUE-F1 was cured by propagating L. casei CP002616 pUE-F1 in MRS without antibiotics for 2 culture passages. Exogenous plasmid was unstable without antibiotics, and Em-sensitive clones were considered pUE-F1-cured strains and were named $L$. casei $\mathrm{CP} 002616 \mathrm{pLC} 2 \mathrm{~W} \Delta-\mathrm{IC}$.

\section{Characterization of EPS and Acid Production}

Mutant strain L. casei CP002616 pLC2W $\Delta$-HT produced $12 \%$ less EPS than the wild-type, whereas the wild-type and IC strains produced similar amounts of EPS (Figure 5a). We proposed that mutations would occur during the process of subculture at high temperature because some mutations will happen during the harsh physical curing process, such as the change of EPS production and delay of acid production.

We analyzed the monosaccharide composition of EPS-HT, EPS-IC, and EPS-WT by HPAEC-PAD. As shown in Table 5, EPS-HT, EPS-IC, and EPS-WT were mainly composed of rhamnose, arabinose, galactose, glucose, and xylose. The monosaccharide composition was similar among EPS of different strains

The results of high-performance gel-permeation chromatography revealed that EPS-HT, EPS-IC, and EPS-WT exhibited similar elution profiles (data not shown), indicating no significant difference in molecular weight distribution among EPS from mutants and wild type. As shown in Table 5, the molecular weights of EPS-HT, EPS-IC, and EPS-WT were 20.64, 20.58, and $20.62 \mathrm{kDa}$, respectively.

Figure 5b compares acid production in L. casei CP002616 pLC2W $\Delta$-HT, L. casei CP002616 pLC2W $\Delta$ IC, and L. casei CP002616 (wild type) under normal growth conditions. Acid production was reduced in $L$. casei CP002616 pLC2W $\Delta$-HT, whereas that of L. casei CP002616 pLC2W $\Delta$-IC was almost equal to that of the wild type. These results showed that there was no relationship between plasmid and production of EPS or acid.

\section{DISCUSSION}

Plasmids are widespread in LAB and usually replicate by RC or theta replication. The biological significance of plasmids in lactobacilli remains unknown but the cryptic plasmids isolated from LAB could be developed as shuttle vectors. Lactobacillus casei TISTR1341 have 3 plasmids: pRCEID2.9 with RC replication and pRCEID3.2 and pRCEID13.9 with theta replication. The

Table 4. Transformation efficiency (cfu/ $\mu \mathrm{g}$ of DNA) and stability (as plasmid loss rate) of pUE-F1 in different hosts

\begin{tabular}{lcc}
\hline Host strain & Efficiency $(\mathrm{cfu} / \mu \mathrm{g}$ of DNA) & Plasmid loss rate $(\%)$ \\
\hline Lactobacillus casei CP002616 & $1.8 \times 10^{5}$ & 52.56 \\
L. casei BDII & $2.2 \times 10^{5}$ & 65.43 \\
L. casei AR341 & $1.7 \times 10^{5}$ & 33.21 \\
Lactobacillus paracasei AR93 & $8.5 \times 10^{4}$ & 13.47 \\
Lactococcus lactis NZ9000 & $1 \times 10^{2}$ & - \\
Lactobacillus plantarum (WCFS1) & - & - \\
Lactobacillus brevis & - & - \\
\hline
\end{tabular}


relative copy numbers per chromosome equivalents of pRCEID-LC2.9 and pRCEID-LC13.9 were about 15 and 4, respectively (Panya et al., 2012). Cryptic plasmid pMC11 was isolated from $L$. casei MCJ and has 2 replicons of distinct types. Each replicon is independent and exhibits similar transformation efficiencies and copy numbers. Both replicons replicate via theta replication (Chen et al., 2014). All these cryptic plasmids

a)

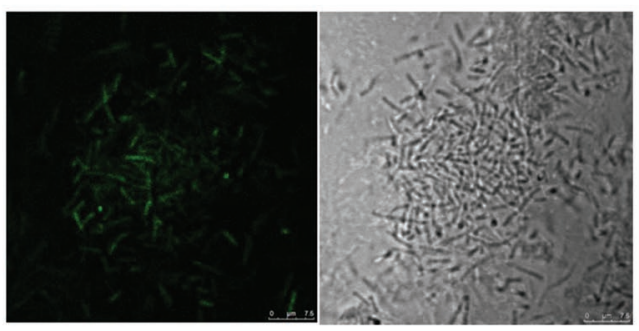

b)

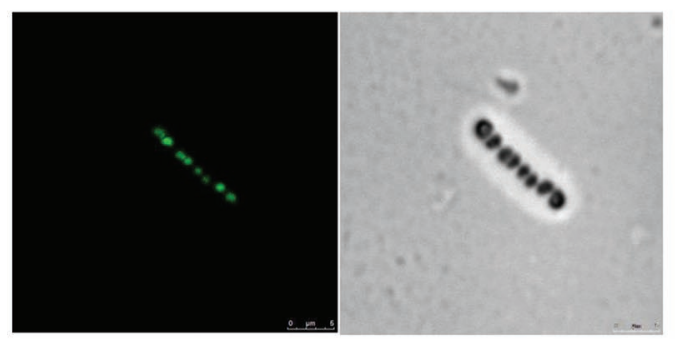

c)

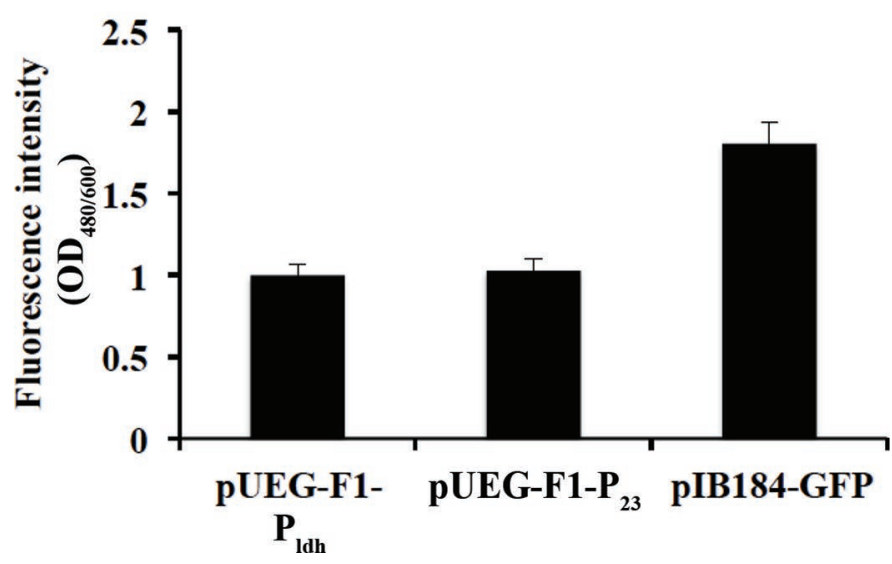

Figure 3. Photograph of cells of lactobacilli species, with fluorescence microscopy (left) and phase contrast microscopy (right) of (a) Lactobacillus casei CP002616, and (b) Lactococcus lactis NZ9000, and (c) green fluorescent protein (GFP) expression (measured as optical density ratio at 480 and $\left.600 \mathrm{~nm}, \mathrm{OD}_{480 / 600}\right)$ of plasmids pUEG-F1- $\mathrm{P}_{\text {ldh }}$, pUEG-F1-P ${ }_{23}$, and pIB184-GFP. Error bars indicate standard deviations. Color version available online. from $\mathrm{LAB}$ were developed to be the shuttle vectors or expression vectors used in LAB.

Here, we studied the cryptic plasmid pLC2W from L. casei CP002616, which can produce 3 types of extracellular polysaccharides (Ai, 2008) and has been sequenced previously. In this report, we compared the AA sequence of the Rep protein of pLC2W with those of theta-type and RC-type plasmids in Lactobacillus. The RepA protein of $\mathrm{pLC} 2 \mathrm{~W}$ belonged to the $\mathrm{RC}$ replication group, based on phylogenetic analysis. Therefore, the replicon of $\mathrm{pLC} 2 \mathrm{~W}$ would replicate via $\mathrm{RC}$ replication. Nucleotide sequence analysis revealed 4 putative ORF related to replication, and we determined that the shortest functional replicon of $\mathrm{pLC} 2 \mathrm{~W}$ contained the origin region and repA.

The new shuttle vectors pUE-F1 developed in this work were shown to replicate in different lactobacilli with a transformation efficiency of $10^{2}$ to $10^{5} \mathrm{cfu} / \mu \mathrm{g}$. This high efficiency made pUE-F1 useful in developing genetic tools in those lactobacilli. To construct an expression vector, we chose $\mathrm{P}_{23}$, a strong promoter that has been used in LAB, and $\mathrm{P}_{\text {ldh }}$, a strong promoter from L. casei CP002616.

Lactobacillus casei CP002616 is an EPS-producing strain and it can help to lower blood pressure (Ai, 2008). Some reports have described the involvement of plasmids in EPS biosynthesis in LAB (Vedamuthu and Neville, 1986; von Wright and Tynkkynen, 1987; Neve et al., 1988). Plasmid pNZ4000 is essential for EPS biosynthesis of Lactococcus lactis (van Kranenburg et al., 1997); however, no evidence indicated a similar result in L. casei. Thus, plasmids are essential for EPS synthesis in some but not all bacteria. Sequence analysis of $\mathrm{pLC} 2 \mathrm{~W}$ showed that there were no ORF involved in EPS synthesis. We speculated there was no relationship between plasmid and EPS production in L. casei CP002616. To prove this hypothesis, we implemented 2 plasmid-curing methods. Several methods have been developed for plasmid curing in different strains, and physical methods are widely used. A cryptic plasmid in Streptococcus lactis was cured by culture at subinhibitory temperature (Gasson and Davies, 1980; Heery et al., 1989). Some chemical methods have been used to eliminate plasmids. For example, plasmid from Streptomycetes was cured using the DNA intercalating agent ethidium bromide, and plasmid-free mutants were obtained (Crameri et al., 1986). Meanwhile, a sequential protoplast generation-recovery process was used to eliminate plasmid $\mathrm{pFP}_{4}$ from Streptomyces FR1 (Chen et al., 2012). Some reports indicate that traditional curing methods can introduce mutational events in strains at high frequency, and these mutations may interfere with the functional analysis of the plasmid (Poppe and 
a)
$1-12$
M
$13-24$

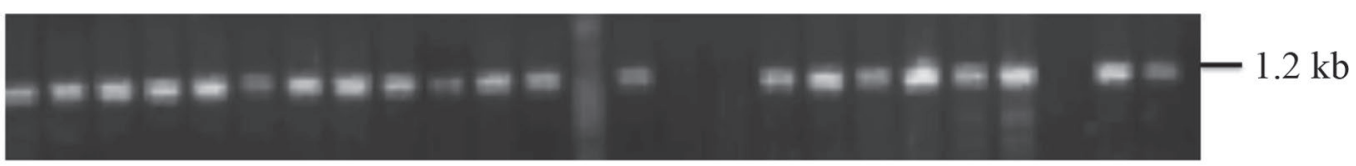

b)
$1-15$
$16 \mathrm{M}$

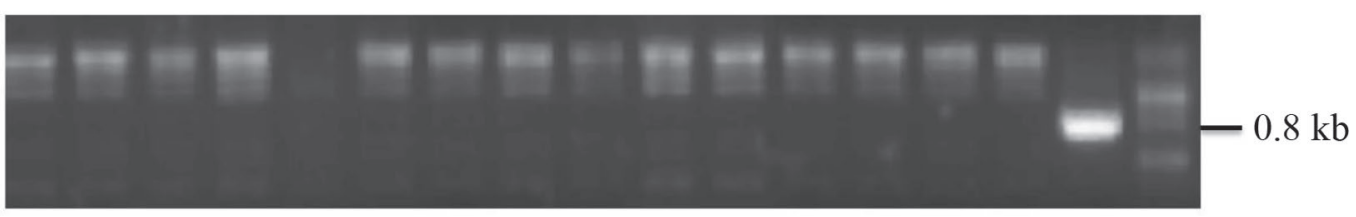

Figure 4. Identification by PCR of the plasmid-cured mutants: (a) high-temperature (HT) method: lanes 1 to $23=$ colonies and lane $24=$ wild-type strain (control); and lane $\mathrm{M}=$ molecular weight marker. The amplified 1.2-kb fragment corresponded to the plasmid-specific gene; (b) plasmid incompatibility (IC) method: lanes 1 to $15=$ colonies; lane $16=$ wild-type strain (control); and lane $\mathrm{M}=$ molecular weight marker. The amplified $0.8-\mathrm{kb}$ fragment corresponded to the plasmid-specific gene on plasmid pLC2W.

Gyles, 1988). Plasmid incompatibility was developed as a milder strategy to cure cryptic plasmid. In this study, we used 2 curing methods (HT and IC) to eliminate the native plasmid pLC2W from L. casei CP002616.

Analysis of monosaccharide compositions and molecular weights of EPS-HT, EPS-IC, and EPS-WT showed no difference between them. Production of EPS and acid were reduced in L. casei CP002616 pLC2W 2 -HT, whereas the plasmid-cured strain L. casei CP002616 pLC2W - -IC showed EPS and acid production similar to that of the wild type. An unexpected mutation might have occurred during the HT plasmid-curing process. The HT method is also labor intensive and

Table 5. Monosaccharide compositions (molar ratio) and molecular weight (MW) of exopolysaccharide (EPS) produced by strains Lactobacillus casei CP002616 pLC2W $\Delta$-HT (plasma cured by heat treatment, HT), L. casei CP002616 pLC2W $\Delta$-IC (plasma cured by incompatibility, IC), and L. casei CP002616 (wild-type, WT), respectively

\begin{tabular}{lccc}
\hline Item & EPS-HT & EPS-IC & EPS-WT \\
\hline Molar ratio & & & \\
Rhamnose & 3.2 & 3.1 & 3.3 \\
Arabinose & 1.0 & 1.2 & 0.9 \\
Galactose & 3.2 & 3.3 & 3.0 \\
Glucose & 2.6 & 2.5 & 2.6 \\
Xylose & 0.1 & 0.1 & 0.2 \\
MW (kDa) & 20.64 & 20.58 & 20.62 \\
\hline
\end{tabular}

time consuming, whereas the IC method is rapid and highly efficient.

In conclusion, we characterized the replication of the novel plasmid pLC2W and constructed a new shuttle vector based on its replication. In addition to the origin region on $\mathrm{pLC} 2 \mathrm{~W}$, the promoter, GFP, and multiple cloning site (MCS) were added to construct the new expression vectors pUEG-F1- $\mathrm{P}_{23}$ and pUEG-F1-P ${ }_{\text {ldh }}$, which could serve as a reporting system in other lactobacilli. In addition, we developed a smaller plasmid pUE-F1 with the same replicon to obtain plasmid-free strains of L. casei CP002616 via the plasmid incompatibility curing method. Sequence analysis of $\mathrm{pLC} 2 \mathrm{~W}$ and plasmid-curing results showed that plasmid $\mathrm{pLC} 2 \mathrm{~W}$ is not involved in EPS synthesis.

\section{ACKNOWLEDGMENTS}

This work was supported by the National Natural Science Foundation of China (No. 31371809, 31771956), New Century Excellent Talents Project of Ministry of Education of China (No. NCET-13-0901), International Cooperation Project of Shanghai Science and Technology Commission (No. 14390711700), Food Technology Foundation of Chinese Institute of Food Science and Technology \& Beingmate (No. 2016-004), and Shanghai Nature Science Fund (15ZR1428900). This research did not involve human participants. 
a)

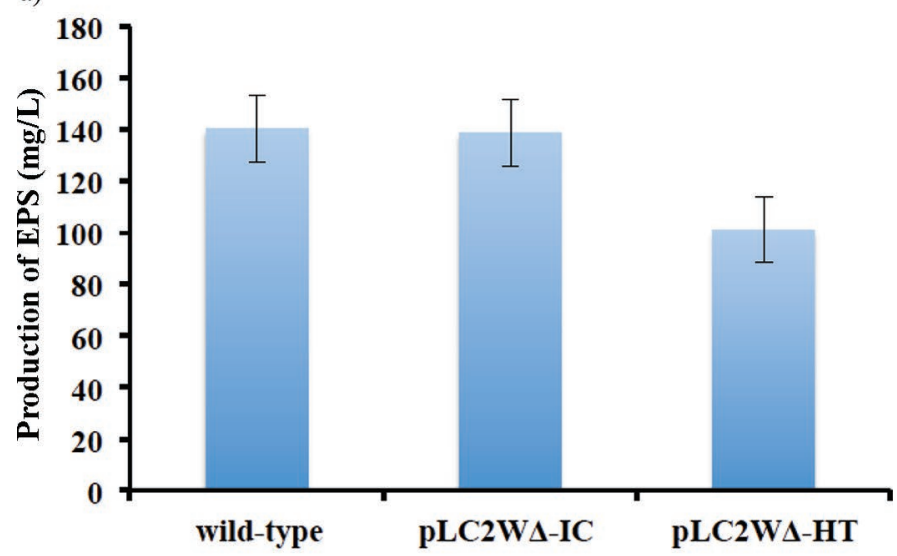

b)

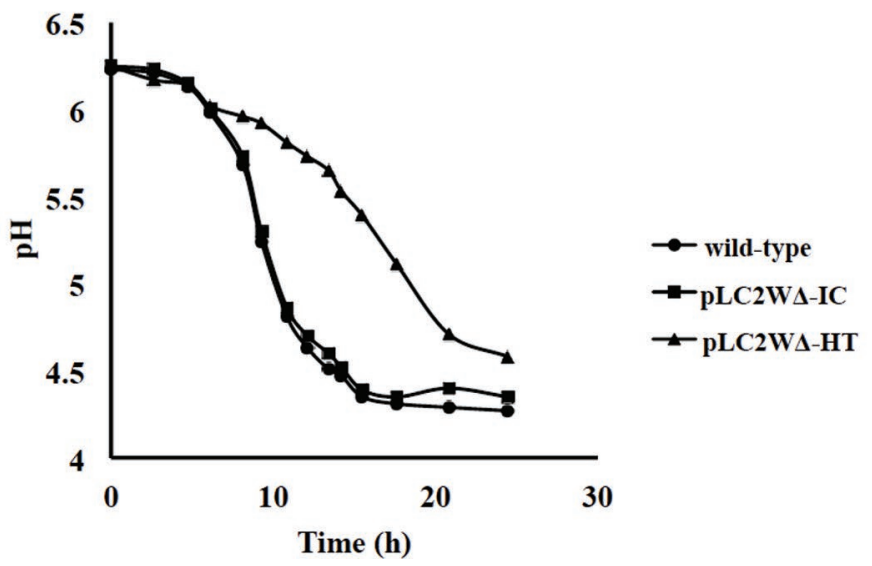

Figure 5. Differences in (a) exopolysaccharide (EPS) production and (b) acid production between the wild-type strain and pLC2W $\Delta$-IC and $\mathrm{pLC} 2 \mathrm{~W} \Delta$-HT (plasmid-cured) mutant strains. Error bars indicate standard deviations. Color version available online.

\section{REFERENCES}

Ai, L., H. Zhang, B. Guo, W. Chen, Z. Wu, and Y. Wu. 2008. Preparation, partial characterization and bioactivity of exopolysaccharides from Lactobacillus casei LC2W. Carbohydr. Polym. 74:4.

Ai, L., C. Chen, F. Zhou, L. Wang, H. Zhang, W. Chen, and B. Guo. 2011. Complete genome sequence of the probiotic strain Lactobacillus casei BD-II. J. Bacteriol. 193:3160-3161.

Aktas, B., T. J. De Wolfe, N. Safdar, B. J. Darien, and J. L. Steele. 2016. The impact of Lactobacillus casei on the composition of the cecal microbiota and innate immune system is strain specific. PLoS One 11:e0156374.

Alvarez-Martín, P., M. O'Connell-Motherway, D. van Sinderen, and B. Mayo. 2007. Functional analysis of the pBC1 replicon from Bifidobacterium catenulatum L48. Appl. Microbiol. Biotechnol. 76:1395-1402.

An, H. Y., and T. Miyamoto. 2006. Cloning and sequencing of plasmid pLC494 isolated from human intestinal Lactobacillus casei: Construction of an Escherichia coli-Lactobacillus shuttle vector. Plasmid 55:128-134.

Bourdichon, F., S. Casaregola, C. Farrokh, J. C. Frisvad, M. L. Gerds, W. P. Hammes, J. Harnett, G. Huys, S. Laulund, A. Ouwehand, I. B. Powell, J. B. Prajapati, Y. Seto, E. Ter Schure, A. Van Boven, V. Vankerckhoven, A. Zgoda, S. Tuijtelaars, and E. B. Hansen.
2012. Food fermentations: microorganisms with technological beneficial use. Int. J. Food Microbiol. 154:87-97.

Chen, C., L. Ai, F. Zhou, L. Wang, H. Zhang, W. Chen, and B. Guo. 2011. Complete genome sequence of the probiotic bacterium Lactobacillus casei LC2W. J. Bacteriol. 193:3419-3420.

Chen, Z., J. Lin, C. Ma, S. Zhao, Q. She, and Y. Liang. 2014. Characterization of pMC11, a plasmid with dual origins of replication isolated from Lactobacillus casei MCJ and construction of shuttle vectors with each replicon. Appl. Microbiol. Biotechnol. 98:59775989 .

Chen, Z., L. Zhong, M. Shen, P. Fang, and Z. Qin. 2012. Characterization of Streptomyces plasmid-phage pFP4 and its evolutionary implications. Plasmid 68:170-178.

Cormack, B. P., R. H. Valdivia, and S. Falkow. 1996. FACS-optimized mutants of the green fluorescent protein (GFP). Gene 173(1 Spec No):33-38.

Crameri, R., J. E. Davies, and R. Hutter. 1986. Plasmid curing and generation of mutations induced with ethidium bromide in streptomycetes. J. Gen. Microbiol. 132:819-824.

Crutz-Le Coq, A. M., and M. Zagorec. 2008. Vectors for lactobacilli and other gram-positive bacteria based on the minimal replicon of pRV500 from Lactobacillus sakei. Plasmid 60:212-220.

de Vos, W. M. 2011. Systems solutions by lactic acid bacteria: From paradigms to practice. Microb. Cell Fact. 10(Suppl. 1):S2.

Desmond, C., R. P. Ross, G. Fitzgerald, and C. Stanton. 2005. Sequence analysis of the plasmid genome of the probiotic strain Lactobacillus paracasei NFBC338 which includes the plasmids pCD01 and pCD02. Plasmid 54:160-175.

Gaspar, P., A. L. Carvalho, S. Vinga, H. Santos, and A. R. Neves. 2013. From physiology to systems metabolic engineering for the production of biochemicals by lactic acid bacteria. Biotechnol. Adv. 31:764-788

Gasson, M. J., and F. L. Davies. 1980. High-frequency conjugation associated with Streptococcus lactis donor cell aggregation. J. Bacteriol. 143:1260-1264.

Gleeson, M., N. C. Bishop, and L. Struszczak. 2016. Effects of Lactobacillus casei Shirota ingestion on common cold infection and herpes virus antibodies in endurance athletes: A placebo-controlled, randomized trial. Eur. J. Appl. Physiol. 116:1555-1563.

Heery, D. M., R. Powell, F. Gannon, and L. K. Dunican. 1989. Curing of a plasmid from E. coli using high-voltage electroporation. Nucleic Acids Res. 17:10131.

Hochwind, K., T. Weinmaier, M. Schmid, S. van Hemert, A. Hartmann, T. Rattei, and M. Rothballer. 2012. Draft genome sequence of Lactobacillus casei W56. J. Bacteriol. 194:6638.

Kato-Kataoka, A., K. Nishida, M. Takada, M. Kawai, H. Kikuchi-Hayakawa, K. Suda, H. Ishikawa, Y. Gondo, K. Shimizu, T. Matsuki, A. Kushiro, R. Hoshi, O. Watanabe, T. Igarashi, K. Miyazaki, Y. Kuwano, and K. Rokutan. 2016. Fermented milk containing Lactobacillus casei strain Shirota preserves the diversity of the gut microbiota and relieves abdominal dysfunction in healthy medical students exposed to academic stress. Appl. Environ. Microbiol. 82:3649-3658.

Kleerebezem, M., J. Boekhorst, R. van Kranenburg, D. Molenaar, O. P. Kuipers, R. Leer, R. Tarchini, S. A. Peters, H. M. Sandbrink, M. W. Fiers, W. Stiekema, R. M. Lankhorst, P. A. Bron, S. M. Hoffer, M. N. Groot, R. Kerkhoven, M. de Vries, B. Ursing, W. M. de Vos, and R. J. Siezen. 2003. Complete genome sequence of Lactobacillus plantarum WCFS1. Proc. Natl. Acad. Sci. USA 100:1990-1995.

Lambert, J. M., R. S. Bongers, and M. Kleerebezem. 2007. Cre-loxbased system for multiple gene deletions and selectable-marker removal in Lactobacillus plantarum. Appl. Environ. Microbiol. 73:1126-1135.

Larkin, M. A., G. Blackshields, N. P. Brown, R. Chenna, P. A. McGettigan, H. McWilliam, F. Valentin, I. M. Wallace, A. Wilm, R. Lopez, J. D. Thompson, T. J. Gibson, and D. G. Higgins. 2007. Clustal W and Clustal X version 2.0. Bioinformatics 23:2947-2948.

Lee, J. H., J. S. Halgerson, J. H. Kim, and D. J. O'Sullivan. 2007. Comparative sequence analysis of plasmids from Lactobacillus del- 
brueckii and construction of a shuttle cloning vector. Appl. Environ. Microbiol. 73:4417-4424.

Liu, X., D. Wang, H. Wang, E. Feng, L. Zhu, and H. Wang. 2012. Curing of plasmid pXO1 from Bacillus anthracis using plasmid incompatibility. PLoS One 7:e29875.

Lokman, B. C., M. Heerikhuisen, R. J. Leer, A. van den Broek, Y. Borsboom, S. Chaillou, P. W. Postma, and P. H. Pouwels. 1997. Regulation of expression of the Lactobacillus pentosus xylAB operon. J. Bacteriol. 179:5391-5397.

Luxananil, P., R. Promchai, S. Wanasen, S. Kamdee, P. Thepkasikul, V. Plengvidhya, W. Visessanguan, and R. Valyasevi. 2009. Monitoring Lactobacillus plantarum BCC 9546 starter culture during fermentation of Nham, a traditional Thai pork sausage. Int. J. Food Microbiol. 129:312-315.

Mathiesen, G., E. Sorvig, J. Blatny, K. Naterstad, L. Axelsson, and V. G. Eijsink. 2004. High-level gene expression in Lactobacillus plantarum using a pheromone-regulated bacteriocin promoter. Lett. Appl. Microbiol. 39:137-143.

Neve, H., A. Geis, and M. Teuber. 1988. Plasmid-encoded functions of ropy lactic acid streptococcal strains from Scandinavian fermented milk. Biochimie 70:437-442.

Ni, B., Z. Du, Z. Guo, Y. Zhang, and R. Yang. 2008. Curing of four different plasmids in Yersinia pestis using plasmid incompatibility. Lett. Appl. Microbiol. 47:235-240.

O'Sullivan, D. J., and T. R. Klaenhammer. 1993. Rapid mini-prep isolation of high-quality plasmid DNA from Lactococcus and Lactobacillus spp. Appl. Environ. Microbiol. 59:2730-2733.

Panya, M., V. Lulitanond, S. Tangphatsornruang, W. Namwat, R. Wannasutta, N. Suebwongsa, and B. Mayo. 2012. Sequencing and analysis of three plasmids from Lactobacillus case $i$ TISTR1341 and development of plasmid-derived Escherichia coli-L. casei shuttle vectors. Appl. Microbiol. Biotechnol. 93:261-272.

Papagianni, M., N. Avramidis, and G. Filioussis. 2007. High efficiency electrotransformation of Lactococcus lactis ssp. lactis cells pretreated with lithium acetate and dithiothreitol. BMC Biotechnol. $7: 15$.

Pfaffl, M. W. 2001. A new mathematical model for relative quantification in real-time RT-PCR. Nucleic Acids Res. 29:e45.

Poppe, C., and C. L. Gyles. 1988. Tagging and elimination of plasmids in Salmonella of avian origin. Vet. Microbiol. 18:73-87.

Serror, P., T. Sasaki, S. D. Ehrlich, and E. Maguin. 2002. Electrotransformation of Lactobacillus delbrueckii subsp. bulgaricus and L. delbrueckii subsp. lactis with various plasmids. Appl. Environ. Microbiol. 68:46-52.

Skulj, M., V. Okrslar, S. Jalen, S. Jevsevar, P. Slanc, B. Strukelj, and V. Menart. 2008. Improved determination of plasmid copy number using quantitative real-time PCR for monitoring fermentation processes. Microb. Cell Fact. 7:6.

Sun, Z., J. Kong, and W. Kong. 2010. Characterization of a cryptic plasmid pD403 from Lactobacillus plantarum and construction of shuttle vectors based on its replicon. Mol. Biotechnol. 45:24-33.

Tamura, K., J. Dudley, M. Nei, and S. Kumar. 2007. MEGA4: Molecular Evolutionary Genetics Analysis (MEGA) software version 4.0. Mol. Biol. Evol. 24:1596-1599.

Uraji, M., K. Suzuki, and K. Yoshida. 2002. A novel plasmid curing method using incompatibility of plant pathogenic Ti plasmids in Agrobacterium tumefaciens. Genes Genet. Syst. 77:1-9.

van de Guchte, M., J. M. van der Vossen, J. Kok, and G. Venema. 1989. Construction of a lactococcal expression vector: Expression of hen egg white lysozyme in Lactococcus lactis ssp. lactis. Appl. Environ. Microbiol. 55:224-228.

van Kranenburg, R., J. D. Marugg, I. I. van Swam, N. J. Willem, and W. M. de Vos. 1997. Molecular characterization of the plasmid-encoded eps gene cluster essential for exopolysaccharide biosynthesis in Lactococcus lactis. Mol. Microbiol. 24:387-397.

Vaughan, E. E., F. Schut, H. G. Heilig, E. G. Zoetendal, W. M. de Vos, and A. D. Akkermans. 2000. A molecular view of the intestinal ecosystem. Curr. Issues Intest. Microbiol. 1:1-12.

Vedamuthu, E. R., and J. M. Neville. 1986. Involvement of a plasmid in production of ropiness (mucoidness) in milk cultures by Streptococcus cremoris MS. Appl. Environ. Microbiol. 51:677-682.

von Wright, A., and S. Tynkkynen. 1987. Construction of Streptococcus lactis subsp. lactis strains with a single plasmid associated with mucoid phenotype. Appl. Environ. Microbiol. 53:1385-1386.

Wen, K. G. Li, T. Bui, F. Liu, Y. Li, J. Kocher, L. Lin, X. Yang, and L. Yuan. 2012. High dose and low dose Lactobacillus acidophilus exerted differential immune modulating effects on $\mathrm{T}$ cell immune responses induced by an oral human rotavirus vaccine in gnotobiotic pigs. Vaccine 30:1198-1207.

Yin, S., Y. Hao, Z. Zhai, R. Li, Y. Huang, H. Tian, and Y. Luo. 2008. Characterization of a cryptic plasmid pM4 from Lactobacillus plantarum M4. FEMS Microbiol. Lett. 285:183-187.

Yin, S., Y. Hao, Z. Zhai, W. Zhang, H. Zhou, G. Wang, X. Shi, and Y. Luo. 2009. Functional analysis of the plasmid pM4 replicon from Lactobacillus plantarum M4: Determination of the minimal replicon and functionality identification of the putative sso. Plasmid $62: 166-171$

Yuan, Q., L. Zhao, Q. Cha, Y. Sun, H. Ye, and X. Zeng. 2015. Structural characterization and immunostimulatory activity of a homogeneous polysaccharide from Sinonovacula constricta. J. Agric. Food Chem. 63:7986-7994. 